\title{
UJIAN SECARA ONLINE BAGI PENDIDIKAN TERBUKA DAN JARAK JAUH
}

\author{
Herman (herman@ut.ac.id) \\ FMIPA Universitas Terbuka
}

\begin{abstract}
Open and Distance Learning (ODL) nowadays becomes a trend in higher education. Course delivery and course materials distribution have already been in electronic form by using information and communication technology (ICT). This technology becomes cheaper and much easier to be used. Indonesia as a nation where its people spread in thousands of islands does not always have face-to-face university in each city. Meanwhile, the need of skilled worker is always increased. ODL then becomes an alternative to educate people by using different way of teaching and learning process. People who have difficulties in accessing face-to-face university can use ODL as an alternative to upgrade their education. The role of ICT in ODL become important since the students can learn by using ICT. The students can also "meet" their colleagues virtually. Meanwhile, it was explored that ICT can be utilized for online examination. Online examination is more efficient, much faster in processing the examination result, and much cheaper in budget. This article discusses many aspects of strength and weakneses which is faced by educational institutions in administering online examinations.
\end{abstract}

Keywords: distance education, online examination

Tak dapat dipungkiri bahwa saat ini pendidikan merupakan suatu industri yang sedang berkembang. Industri ini dikendalikan oleh kompetisi antara keberadaan pendidikan itu sendiri dengan para peminatnya yang menuntut lebih banyak kelenturan dalam pelaksanaan pendidikan itu. Agar dapat terus hidup dalam keadaan kompetisi seperti ini, dibutuhkan suatu pendekatan alternatif terhadap pelaksanaan pendidikan tradisional yang ada selama ini (Bernardes, 2003).

Tuntutan perubahan ini disebabkan oleh kebutuhan akan transformasi di lingkungan pendidikan itu sendiri. Berdasarkan sejarah, pendidikan merupakan monopoli dari bisnis (O'Donoghue, Jentz, Singh, \& Molyneux, 2000). Namun demikian, dengan adanya perkembangan dalam dunia teknologi dan juga dengan adanya perubahan sikap terhadap proses pembelajaran maka cara pandang baru tentang pembelajaran juga mempengaruhi pandangan pasar.

Hasil riset menunjukkan bahwa dunia pendidikan haruslah melibatkan teknologi informasi dan komunikasi (TIK). Menurut O'Donoghue, Singh, dan Dorward (2001), pemanfaatan TIK secara optimal dalam pendidikan dapat membuat: 1) hasil pendidikan menjadi lebih berkualitas, 2) pembelajaran menjadi jauh lebih cair, tidak kaku dan lebih fleksibel, 3) efisiensi biaya, 4) kualitas bahan ajar menjadi lebih baik karena banyak sekali fitur yang tersedia di sana, dan 5) posisi dan peran guru/dosen menjadi berubah.

Pendidikan tradisional tidak pernah mempertimbangkan bahwa manusia secara konsep memiliki kemampuan menggali informasi yang lebih banyak bila dibandingkan dengan informasi yang dapat diserap oleh individu. Pada masa lalu, informasi dipandang memiliki keterbatasan dan setiap orang bila diberi waktu yang cukup akan dapat menyerap semua informasi di dalamnya. Namun 
demikian, bertentangan dengan keadaan tersebut, informasi yang ada saat ini sangatlah banyak bahkan sangat berlebihan (Gillani, 2003). Sebagian besar informasi tersebut saat ini berada di dalam dunia maya (virtual world).

Pada tahun 1995, beberapa professional dalam bidang pendidikan yang mengerti tentang TIK menghadiri presentasi multimedia yang diberikan oleh Brandon Hall. Mereka ini mengikuti pelatihan dengan menggunakan CD-ROM. Para peserta tertarik untuk mengetahui lebih banyak tentang teknologi itu beserta aplikasinya. Pada tahun 1996, American Society for Training and Development (ASTD) melakukan satu workshop pada seminar tahunan mereka dengan menggunakan internet. Pada tahun 2000, John Chambers, kepala Cisco System, Inc menyatakan bahwa "e-learning is the next killer app." Pada seminar itu, setiap orang mempelajari paradigma baru yaitu e-learning (Van Dam, 2004).

Gagasan tentang e-learning ini kemudian digunakan untuk pelaksanaan ujian secara online. Kumpulan soal-soal ujian diletakkan pada bank soal. Para mahasiswa dari banyak lokasi, dengan waktu atau jadwal yang dapat mereka pilih sendiri melakukan ujian online sebagai pengganti ujian tertulis (paper and pencil). Sebagaimana ujian tertulis, ada aturan yang harus diikuti agar pelaksanaan ujian online dapat berjalan dengan baik.

\section{Ujian Online}

Khare dan Lam (2008) menyatakan bahwa isu tentang keharusan melaksanakan ujian secara online pada institusi Pendidikan Terbuka dan Jarak Jauh (PTJJ) sudah tidak dapat dikesampingkan atau ditunda lagi. TIK yang ada saat ini akan sangat menolong dunia pendidikan terutama proses pembelajaran para pelakunya. Dengan memanfaatkan teknologi untuk proses pembelajaran termasuk untuk evaluasi/ujian banyak hal yang dapat dihemat sehingga efisiensi dapat terlaksana. Paling tidak penggunaan kertas akan sangat banyak berkurang. Pengiriman bahanbahan berupa buku (kertas) banyak terkurangi karena peserta hanya perlu mengunduh (download) dari internet. Hampir semua bahan yang berupa kertas dapat diubah menjadi bentuk elektronik berupa file-file komputer yang dapat dicetak. Perlu juga diketahui bahwa ujian dengan cara online ini dapat meningkatkan efisiensi pelaksanaan ujian pada proses pendistribusian bahan-bahan ujian, pengadministrasiannya, tempat penyimpanan set soal-soal ujiannya, dan juga pada proses penilaiannya (Brinke, 2009).

Menurut Barkley (2002), penggunaan ujian secara online dapat menolong para dosen/instruktur di universitas mencapai tujuan-tujuan instruksional dan pedagogikal. Hal lain yang dapat diperoleh adalah 1) banyaknya alat ukur yang digunakan untuk menilai hasil belajar mahasiswa, 2) mengurangi biaya yang dibutuhkan untuk menilai ujian, 3) dapat memberikan feedback kepada mahasiswa dengan cepat, dan 4) mengurangi biaya perbanyakan naskah ujian.

Analisis biaya yang dilakukan oleh Robertson (2005) menghasilkan informasi bahwa ujian online dapat menghemat banyak dana di universitas. Selain itu, studi tersebut menyimpulkan bahwa metoda ujian secara online mampu memproses jawaban ujian dengan sangat cepat untuk menghasillkan nilai/grade. Metoda ini hanya membutuhkan ongkos yang jauh lebih sedikit bila dibandingkan ongkos dengan menggunakan cara konvensional. Di samping itu, faktor campur tangan dosen dalam proses penilaian hampir tidak ada. Sudah tentu akan terjadi efisiensi waktu bila pelaksanaan ujian menggunakan cara ini.

Sebagian besar mahasiswa yang menjadi responden pada penelitian Robertson (2005) setuju bahwa proses evaluasi dengan cara online sangat cepat dan lebih menyenangkan bagi mereka. Penelitian dan analisis pada studi tersebut menunjukkan fakta bahwa hasil ujian, baik itu 
berupa ujian tertulis biasa maupun dengan cara online akan menghasilkan skor atau nilai yang stabil dan konsisten.

Teknologi sebagai suatu alat dapat difungsikan secara optimal untuk membantu pelaksanaan pembelajaran. Selama alat itu aman digunakan maka ia akan dapat sangat membantu. E-learning dan e-evaluation pada dasarnya adalah bagaimana memanfaatkan teknologi untuk membantu mengoptimumkan hasil pendidikan. (Van Dam, 2004). Namun demikian memang dapat terlihat bahwa perubahan dari ujian tertulis menjadi ujian online tidak terjadi dengan cepat.

Ada beberapa alasan yang dapat menjelaskan penyebab lambatnya adopsi ujian online. Menurut Khare and Lam (2008), ujian online memberi kesempatan kepada mahasiswa memperoleh informasi pelengkap dan informasi lainnya yang berkaitan dengan teori ataupun konsep pada masalah tertentu. Informasi ini akan digunakan untuk membuat asumsi-asumsi yang dibutuhkan berkaitan dengan soal-soal ujian. Selain itu, Barkley (2002) memberikan beberapa alasan tentang lambatnya adopsi ujian online. Alasan-alasan tersebut antara lain adalah 1) tuntutan adanya software dan hardware tertentu, 2) isu tentang lebih terbukanya peluang untuk berbuat curang, 3) berkurangnya interaksi sosial dan pendekatan antar manusia, 4) terbatasnya sarana logistik seperti ruang dan waktu yang tersedia.

\section{Keamanan Pelaksanaan PTJJ Melalui WEB}

World Wide Web (web) memfasilitasi atau meyediakan pelayanan dalam bentuk yang baru kepada para peserta didiknya. Hal ini dapat lebih dirasakan oleh peserta didik yang jauh dari kampus pusat. Fasilitas ini menyediakan kemudahan dalam proses pembelajaran. Namun demikian selain kemudahan, fasilitas melalui web juga memiliki masalah, yaitu keamanan (security). Resiko terletak pada sistem dan data/informasi yang ada di sana, dan hampir setiap orang dapat mengakses data tersebut. Kalau sistem terganggu karena masalah perangkat keras/lunak dan pendukungnya maka perbaikannya tidak terlampau sulit. Dengan penyempurnaan/perbaikan pada masalah tersebut maka masalah akan selesai. Tetapi, bagaimana jika sistem atau data diganggu oleh orang yang memang berniat mengganggu? Penanganan kasus ini memang harus dikembangkan dengan cara mengantisipasi sebanyak mungkin kemungkinan yang dapat terjadi. Keamanan pelaksanaan PTJJ melalui web sangatlah mendasar karena keamanan menyangkut kepercayaan pengguna terhadap sistem yang ditawarkan (.Adams \& Blandford, 2003).

Walaupun faktor keamanan adalah hal penting dan mendasar pada pelaksanaan PTJJ, jangan sampai hal ini memperlambat usaha pemanfaatannya bagi kepentingan pendidikan. Memang mekanisme implementasi untuk mempertinggi keamanan banyak yang tidak bagus atau bahkan gagal mencapai tujuan. Tetapi usaha perbaikannya harus selalu dilakukan.

Terdapat dua isu tentang keamanan pada pemanfaatan web yaitu pemeriksaan keabsahan pengguna (authentication) dan privasi pengguna (.Adams \& Blandford, 2003). Persoalan pertama yang dihadapi pengguna adalah pada prosedur pemeriksaan keabsahan yang menyulitkan pengguna seperti password. Akibatnya banyak pengguna mencoba menghindari mekanisme itu atau mencari cara lain untuk menyelesaikan tugas-tugas mereka (Adam \& Sasse, 1999, Holmstrom, 1999, Whitten \& Tygar, 1999, Preece, 2000). Para pengguna juga cenderung melindungi privasi mereka terhadap pertanyaan-pertanyaan yang muncul. Isu seperti ini biasanya berkaitan dengan konsep kepemilikan (seperti hak kepemilikan intelektual, copyrights, hak-hak privasi). Banyak sistem PTJJ online tidak menyediakan feedback yang memadai kepada pengguna tentang kontrol terhadap hak-hak mereka. Walaupun beberapa isu hanya berkaitan dengan pengaturan tentang PTJJ online yang spesifik, 
tetapi masalah yang lebih umum juga dapat terjadi (Adams, 1999, Bellotti \& Sellen, 1993, Preece, 2000).

Menurut Adams dan Blandford (2003) agar mekanisme pengamanan PTJJ online dapat efektif mengamankan informasi, mereka harus dirancang sedemikian rupa dengan mempertimbangkan kebutuhan pengguna. Kebergunaan pengamanan ini berkaitan dengan penyediaan kontrol yang cukup terhadap keamanan data pengguna. Para pengguna dapat merupakan penyedia/penulis materi ajar yang tidak ingin tulisannya diubah-ubah orang lain. Bila pengguna adalah peserta didik, mereka ingin jawaban ujian mereka aman, atau hasil ujian mereka juga aman.

Sudah pasti keamanan data merupakan hal vital pada PTJJ online. Keamanan informasi harus dibuat sedemikian rupa sehingga hanya orang-orang yang berhak saja yang dapat terlibat di dalamnya. Menurut Newmann (1995), keamanan komputer cenderung tertuju pada penyalahgunaan oleh manusia daripada kesalahan komputer itu sendiri. Ada dua aspek penting untuk keamanan ini yaitu kepercayaan (confidentiality) dan integritas (integrity). Kepercayaan cenderung pada pengamanan informasi dari orang-orang yang tidak memiliki hak untuk mengakses. Sedangkan, integritas mengacu kepada pemeliharaan keadaan yang tidak seimbang antara sistem dan penggunaan data. Kedua hal ini sangat berkaitan dengan usaha bahwa penyalahgunaan yang mungkin terjadi tidak akan berakibat pada keandalan komputer. Jadi pada prinsipnya keamanan haruslah dapat menjamin bahwa mereka yang berhak menggunakan fasilitas pada PTJJ online harus dapat mengaksesnya tanpa kuatir akan keamanannya.

Untuk menjaga keseimbangan seperti yang telah dijelaskan maka harus ada tindakan pemeriksaan tentang yang berhak dan tentang kepemilikan. Hal ini dilakukan karena informasi yang disediakan hanyalah untuk mereka yang memang mempunyai hak menggunakannya (Preece, 2000).

Isu keamanan seringkali juga tidak secara langsung diperhatikan oleh administrator PTJJ online. Tulisan-tulisan tentang keamanan data pada PTJJ cendrung terpusat pada isu-isu hak-hak intelektual dan copyright (Diotalevi, 2000; McAlister, Rivera, \& Hallam, 2001). Tetapi tulisan-tulisan yang terbaru membahas tentang user feedback dan assessment (Batemen, 2000; McAlister, et al, 2001). McAlister et al menyatakan bahwa pemeriksaan identitas pengguna adalah sangat penting terlebih lagi bila digunakan untuk mengakses data kemajuan peserta didik. Namun demikian proses pemeriksaan keabsahan pengguna ini selalu menghadapi persoalan pada prosedur pemeriksaan yang seringkali menyusahkan pengguna.

\section{Ujian di Universitas Terbuka}

Universitas Terbuka (UT) adalah salah satu institusi pendidikan yang menawarkan PTJJ kepada mahasiswanya. Jumlah mahasiswa yang terdaftar di UT saat ini sekitar 600.000 orang, yang sebagian besar terdiri dari mahasiswa S1 Pendidikan Guru Sekolah Dasar ( $\mathrm{S}_{1}$ PGSD) dan mahasiswa program studi lainnya di empat fakultas yang ada. Saat ini sebagian besar mahasiswa UT belajar dari bahan ajar cetak (modul) dan didukung oleh beberapa macam tutorial seperti tutorial tatap muka dan tutorial online. UT menawarkan sekitar 1200 matakuliah kepada mahasiswanya yang tersebar di 36 program studi (UT, 2009). Jumlah matakuliah yang ditutorkan secara online sampai dengan akhir tahun 2010 adalah 522 matakuliah. Semua matakuliah ini setiap semesternya diujikan dengan cara paper-and-pencil-test.

Karena mahasiswa UT tersebar di hampir semua provinsi yang ada di Indonesia, maka UT memiliki "kantor cabang" di 37 tempat di semua provinsi. Kantor cabang ini dinamakan Unit Program 
Belajar Jarak Jauh (UPBJJ). Mahasiswa/calon mahasiswa UT meregistrasikan keikutsertaan mereka dalam UT melalui kantor UPBJJ ini.

Dengan jumlah matakuliah sebesar itu dan dengan besarnya jumlah mahasiswa yang tersebar di seluruh Indonesia, dapat dibayangkan bagaimana rumitnya pelaksanaan ujian yang dilaksanakan UT setiap semesternya. Banyak sekali kertas yang dibutuhkan untuk naskah ujian, beserta kelengkapan lainnya seperti kertas jawaban ujian. Pencetakan naskah dan penataan naskah ujian dengan jumlah sebesar itu sudah pasti sangat rumit. Penataan naskah ujian di UT Pusat dan pendistribusiannya di lokasi ujian sudah tentu memerlukan waktu panjang dan ketelitian yang sangat tinggi. Kegiatan-kegiatan itu dilakukan UT pada setiap semester. Perlu diketahui bahwa di setiap semester pada program studi tertentu dibutuhkan waktu 3 hari untuk melaksanakan ujian.

Dibutuhkan ruang ujian yang sangat banyak untuk menampung mahasiswa peserta ujian. Selain itu juga dibutuhkan tenaga manusia yang banyak dalam proses pelaksanaan ujian sejak persiapan ujian sampai mengeluarkan hasil ujiannya.

Secara ideal kalau ujian online dapat dipersiapkan dengan benar setelah mempertimbangkan kemungkinan memperkecil resiko-resiko yang terjadi maka banyak sekali hal yang dapat disederhanakan. Penyederhanaan ini akan berdampak pada semakin tingginya tingkat ketelitian, semakin cepatnya proses pelaksanaan ujian, semakin cepatnya hasil ujian yang diperoleh mahasiswa, dan semakin banyak penghematan dana yang dapat diperoleh.

Pada pelaksanaan ujian secara tertulis, UT harus mempersiapkan bahan ujian sebanyak matakuliah yang diregistrasikan oleh mahasiswa. Kalau saja ada 300.000 mahasiswa yang ikut ujian dan masing-masing meregistrasi 10 matakuliah maka UT harus menyediakan 3.000 .000 naskah ujian. Asumsikan bahwa tiap kelas menampung 20 mahasiswa peserta ujian, maka dibutuhkan 150.000 ruang ujian. Bila setiap ruang perlu 2 pengawas ujian, berarti dibutuhkan 300.000 pengawas. Belum lagi sejumlah tenaga lainnya yang diperlukan untuk mendukung pelaksanaan ujian. UT biasanya bekerja-sama dengan sekolah setempat untuk penyediaan ruang-ruang ujian dan pengawas ujian. Sejumlah besar sekolah di tiap kota UPBJJ akan digunakan sebagai tempat ujian bagi para mahasiswa.

Saat ini UT sedang mengembangkan sistem ujian secara online. UT sendiri memang sudah memiliki saluran sendiri untuk kepentingan yang berkaitan dengan dunia maya. Sistem ujian online ini sudah diujicobakan di beberapa lokasi. Hasil yang diperoleh cukup memuaskan. Hanya saja ujicoba baru terlaksana untuk sejumlah kecil mahasiswa. Bagaimana kalau sejumlah besar mahasiswa mengikuti ujian secara bersamaan pada waktu yang sama? Apakah bandwidth yang dimiliki UT mampu menanganinya? Apakah UT memiliki tempat-tempat dan ruang-ruang ujian yang mampu menampung peserta ujian dalam jumlah besar?

\section{KEMUNGKINAN PELAKSANAAN UJIAN ONLINE DI UT}

Bagi institusi pendidikan dengan sistem PTJJ, pelaksanaan ujian online memang harus dipersiapkan dengan matang. Hal-hal yang harus dipertimbangkan antara lain adalah: 1) besarnya bandwidth yang akan digunakan, 2) jumlah komputer yang akan digunakan, 3) jumlah 'ruang-ujian" yang akan digunakan,

Bandwidth untuk lingkungan UT sendiri mungkin tidak terlampau bermasalah. UT memiliki saluran komunikasi sendiri yang berkaitan dengan dunia maya. Selain untuk internet dan video conference, UT juga menggunakan saluran tersebut untuk hubungan telepon antar UPBJJ dan pusat. Untuk ujian online yang diadakan di UPBJJ, tampaknya UT juga tidak mempunyai masalah karena infrastrukturnya sudah siap. 
Namun demikian, UT membutuhkan lokasi ujian online di luar yang sudah dimiliki UT saat ini. Untuk itu, sebaiknya UT berkolaborasi dengan sekolah-sekolah yang memiliki lab komputer dari pada membangun infrastruktur baru untuk kepentingan ujian online. Selain itu, kerjasama dengan sekolah adalah suatu hal yang sudah biasa dilakukan oleh UT. Untuk kepentingan ujian online, UT selayaknya memperbesar bandwidth yang ada di sekolah-sekolah yang akan digunakan. Dana untuk investasi penambahan bandwidth akan jauh lebih sedikit dibandingkan bila UT harus menyediakan sendiri infrastructrure untuk ujian online. Investasi ini selain digunakan untuk kepentingan UT, juga dapat dimanfaatkan oleh sekolah-sekolah tersebut. Kriteria pemilihan sekolah selain memiliki sejumlah komputer yang terhubung dengan jaringan internet, juga yang terletak di lokasi-lokasi yang dekat dengan domisili mahasiswa.

Selama ini pada pelaksanaan ujian, setiap ruang ujian diperuntukkan bagi 20 peserta. Karena itu, lab komputer yang dipilih paling tidak harus memiliki 20 komputer yang dapat digunakan. Bagaimana jika sekolah yang terpilih hanya memiliki komputer kurang dari 20? Ada baiknya UT juga menambahkan komputer di sana sehingga menjadi 20. Sekolah-sekolah terpilih ini nantinya tentu akan terus digunakan oleh UT pada saat pelaksanaan ujian online. Selain itu, komputer tambahan ini juga dapat dimanfaatkan oleh murid-murid sekolah tersebut, sehingga penggunaannya dapat lebih optimal lagi.

Pemilihan jumlah sekolah yang memiliki lab komputer disesuaikan dengan jumlah ruangan yang dibutuhkan. Kalau seandainya satu sekolah dapat mengadakan ujian untuk 20 mahasiswa dalam satu hari dan waktu yang tersedia adalah hari Sabtu dan Minggu, maka satu sekolah dapat menampung 40 mahasiswa per minggunya. Misalkan peserta ujian ada 300.000, maka dibutuhkan $300.000 / 40=7.500$ sekolah di Indonesia yang memiliki lab.komputer. Itu kalau pelaksanaan ujian dilakukan hanya 2 hari yaitu Sabtu dan Minggu. Hari pelaksanaan ujian dapat diperlebar menjadi 7 hari/minggu, dengan catatan untuk hari Senin sampai Jumat, pelaksanaan ujian dilakukan setelah jam sekolah selesai. Kalau ini yang dilakukan maka jumlah sekolah yang dipilih sebagai lokasi ujian akan menjadi lebih sedikit.

Bagaimana tentang keamanan ujian? Sekolah-sekolah yang terpilih sebagai tempat/lokasi ujian dapat didata. Artinya diluar alamat sekolah-sekolah ini, tidak ada ujian UT online yang dapat diakses. Sehingga kalau ada orang yang mencoba masuk atau ikut ujian di luar sekolah yang terdaftar, maka usaha itu akan gagal.

Soal-soal ujian untuk tiap matakuliah yang tampil, kemunculannya dibuat random. Dengan demikian nomor soal yang muncul di satu tempat akan berbeda dengan nomor soal yang muncul di komputer sebelahnya. Option jawaban ujian juga dapat dibuat random. Teknik-teknik ini akan memperkecil kemungkinan kerjasama antara peserta ujian yang duduk bersebelahan. Selain itu, pengawas ujian juga tetap berperan banyak pada saat ujian berlangsung. Peserta ujian harus benarbenar peserta ujian yang sebenarnya. Tidak boleh terjadi ada joki yang melakukan ujian. Karena itu, pemeriksaan identitas harus ketat, sehingga tidak ada orang lain kecuali peserta ujian yang dapat mengikuti ujian online di lokasi ujian. Pemeriksaan ini adalah tugas pengawas ujian.

Pemantauan dari UT pusat dapat terus dilaksanakan seperti pelaksanaan ujian tertulis. Jadi untuk kemanan pelaksanaan ujian, selain pengawasan dari sisi perangkat lunak pengawasan secara fisik juga tetap dilakukan. Pengawas ini bertugas seperti pada ujian tatap muka yaitu mengawasi proses pelaksanaan ujian di ruang kelas (lab komputer). Para pengawas ini yang biasanya terdiri dari guru-guru sekolah yang didampingi pengawas independen harus bekerjasama untuk menjamin agar pelaksanaan ujian online dapat berlangsung tertib. 


\section{PENUTUP}

Bagi institusi pendidikan yang menyelenggarakan sistem PTJJ dan memiliki mahasiswa dengan jumlah besar serta terdistribusi di banyak tempat maka ujian secara online sangat dianjurkan. Memang dibutuhkan infrastruktur yang memadai untuk menunjang pelaksanaan ujian online ini. Namun kunci agar pelaksanaan ujian dengan cara tersebut dapat berjalan dengan baik dan murah adalah dengan melakukan kolaborasi. Di Indonesia sudah banyak sekolah-sekolah, baik itu sekolah umum maupun kejuruan yang sudah memiliki lab komputer. Dengan bekerjasama yang saling menguntungkan bagi ke dua belah pihak, maka penyelenggaraan ujian online akan jauh lebih mudah. Pengembangan sistem ujian online sendiri harus dilakukan oleh institusi penyelenggara PTJJ.

Banyak hal yang dapat dihemat bila ujian paper and pencil diubah menjadi ujian online. Kertas dapat dihemat, gudang-gudang penyimpanan naskah ujian dan kelengkaapannya tidak banyak lagi diperlukan, proses pengiriman naskah ujian serta pendistribusiannya tidak lagi dilakukan secara manual, umpan balik hasil ujian untuk setiap peserta akan segera diketahui begitu peserta selesai ujian. Ini semua berdampak pada efisiensi dan penghematan biaya yang sangat besar. Penggunaan waktu yang dapat dipotong dari ujian biasa ke ujian online juga sangat banyak.

Karena sedemikian banyaknya efisiensi yang dapat terjadi, maka SDM di institusi PTJJ tersebut dapat memanfaatkan waktu dan dana yang ada untuk pengembangan diri dan pengembangan institusi. Namun demikian, perubahan dari pekerjaan yang bersifat lebih administratif ke pekerjaan yang lebih akademis membutuhkan waktu untuk penyesuaian diri. Karena itu, pergeseran paradigma ini perlu dikelola dengan baik. Kalau tidak maka efisiensi yang terjadi tidak dapat dimanfaatkan secara optimal, sehingga sangat disayangkan kalau kesempatan yang ada ini tidak dapat dimanfaatkan oleh institusi PTJJ.

\section{REFERENSI}

Adams, A. \& Sasse, M.A. (1999). The user is not enemy. Communication of the ACM, 42(12), 40-46.

Adams, A. (1999). The implication of users' privacy perception on communication and information privacy policies. Dalam Preceedings of telecommunications Policy ResearchConference (pp. 65-67). Alexandria: TPRC. Press.

Adams, A., \& Blandford, A. (2003). Security and online learning: To protect or prohibit, dalam Usability Evaluation of Online Learning Programs. Claude Ghaoui, ed.). Hershey: Integrated Book Technology.

Barkley, A.P. (2002). An analysis of online examinations in college courses. Diambil 17 Pebruari 2010 dari http://www.techlearning.com/. http://proquest.umi.com/pqdweb?index=7\&did=1146685491\&SrchMode=1\&sid=5\&Fmt=6\&VI nst=PROD\&VType=PQD\&RQT=309\&VName=PQD\&TS=1266400274\&clientld=121000.

Batemen, b. (2000). Talking tech. security and passw**s. Tech Learning (Online Journal) CMP Media, Inc. http://www.techlearning.com/db_area/archives/ WCE/batetek5.ht

Bellotti, V. \& Sellen, A. (1993). Designing of privacy in ubiquitous computing environments. Dalam Proceedings of ECSCW'93, the $3^{\text {rd }}$ European Conference on Computer-Supported Cooperative Work (pp.77-92). Milano: Kluwer Academic Press.

Bernardes, J. (2003). Implementing online delivery and learning support systems: Issues, evaluation and lessons, in C. Ghaoui (ed.), Usability Evaluation of Online Learning Programs, London: Integrated Book Technology. 
Brinke, D.J. (2009). Improving the validity of assessments in computer based assessment. Diambil tanggal 15 April 2010, dari http://www.ou.nl/Docs/Campagnes/ICDE2009/ Papers/Final paper 078joostentenbrinke.pdf.

Diotalevi, R.N. (2000). The digital milennium in copyright. Online Journal of Distance Learning Adminstration, 3(2). http://www.westga.eduhttp://www.wes/ distance/ diotalevi32.html.

Gillani, B.B. 2003. Learning theories and the design of e-learning environments. Maryland: University Press of America.

Holmstrom, U. (1999). User-centered design of security software. Proceedings of Human Factors in Telecommunications. Diambil 12 Juni 2002, dari http://impcs3.hhi.de/HFT/HFT99/ design_99.htm\#5.

Khare, A. \& Lam, H. (2008). Assessing student achievement and progress with online examinations: Some Pedagogical and Technical Issues. Diambil tanggal 17 Pebruary 2010, dari http://proquest.umi.com/pqdweb?index=4\&did=1552846401\&SrchMode=1\&sid= 4\&Fmt=6\&VInst=PROD\&VType=PQD\&RQT=309\&VName=PQD\&TS=1266400023\&clientld= 121000.

McAlister, M.K., Rivera, J.C., \& Hallam, S.F. (2001). Twelve questions to answer before offering a web based curriculum. Journal of Distance learning Administration, 4(3). http://www.westga.edu/ distance/ojdla/summer42/mcalister42.html.

Neumann, P.G. (1995). Computer related risk. New York: ACM Press.

O'Donoghue, J., Jentz, A.,Singh, G., \& Molyneux, S. (2000). IT developments and Cahnge in Customer Demand in Higher Education. Asynchronous Learning Networks, 4(1) dari http://www.aln.org/alnweb/magazine/maga_v4_il.htm.

O'Donoghue, J., Singh,G., \& Dorward,L. (2001). Virtual education in universities: A technological imperative. British Journal of Educational Technology, 32(5), 517-530.

Preece, J. (2000). Online Communities. Chichester: Willey.

Robertson, P.J. (2005). Online Versus In-Class Faculty Evaluation: Does Mode Really Matter?. Diambil tanggal 17 Pebruary 2010, dari http://proquest.umi.com/pqdweb?index=19\&did= $1027494691 \&$ SrchMode=1\&sid=8\&Fmt=6\&VInst=PROD\&VType=PQD\&RQT=309\&VName= PQD\&TS=1266400919\&clientld=121000.

Tim Penulis UT. (2008). Katalog Universitas Terbuka 2009. Jakarta: Universitas Terbuka. Van Dam, N. (2004). The e-Learning: Field Book. New York: McGraw-Hill.

Whitten, A. \& Tygar, J.D. (1999). Why johnny can't encrypt: A usability evaluation of PGP 5.0. Proceedings of the $8^{\text {th }}$ USENIX Security Symposium. Diambil 12 Juni 2002, dari http://www.cs.cmu.edu/ alma/johny.pdf. 